\title{
Effects of Successful Percutaneous Transluminal Coronary Angioplasty on Global and Regional Left Ventricular Function in Unstable Angina Pectoris
}

\author{
PIM J. DE FEYTER, MD, HARRY SURYAPRANATA, MD, PATRICK W. SERRUYS, MD, \\ KEVIN BEATT, MD, MARCEL VAN DEN BRAND, MD, and PAUL G. HUGENHOLTZ, MD
}

\begin{abstract}
Sixty-eight patients (58 men, 10 women, mean age 56.3 years, range 31 to 72 ) with unstable angina pectoris, either initially stabilized with or refractory to optimal pharmacologic treatment, were studied to determine whether regional dysfunction due to stunning of the myocardium caused by attacks of chest pain at rest could be improved with percutaneous transluminal coronary angioplasty (PTCA). Patients were included in the study if they had successful 1vessel PTCA, no angiographic restenosis, no reocclusion or late myocardial infarction and 2 serial left ventriculograms of sufficient quality to allow automated contour analysis before and after PTCA.
\end{abstract}

Global ejection fraction increased significantly (from $56 \%$ to $60 \%$, p <0.05) only after successful dilatation of a stenosis of the left anterior descending coronary artery. Analysis of regional wall displacement showed significant improvement of regional wall motion in the areas supplied by the dilated vessel of either the left anterior descending, the left circumflex or the right coronary artery. Thus, regional myocardial dysfunction due to stunning of the myocardium in patients with unstable angina improves after successful PTCA.

(Am J Cardiol 1987;60:993-997)
$P$ rofound and prolonged myocardial ischemia that does not progress to necrosis may stun cardiac muscle and produce functional, metabolic and structural changes. ${ }^{1-3}$ In patients with unstable angina, abnormalities in regional rest cardiac wall motion may be a result of prolonged attacks of transient ischemia. Regional myocardial dysfunction has been shown to improve after restoration of an adequate blood flow in animal experiments, ${ }^{4-6}$ after coronary bypass surgery $^{7-10}$ and after coronary artery reperfusion in acute myocardial infarction, either by clot lysis or direct percutaneous transluminal coronary angioplasty (PTCA).11-13 This study determines whether regional myocardial dysfunction due to stunning of the myocardium caused by attacks of transient ischemia at rest can be improved with successful PTCA in patients with unstable angina.

From Thoraxcenter, Erasmus University, Rotterdam, The Netherlands. Manuscript received March 3, 1987; revised manuscript received June 30, 1987, accepted July 1, 1987.

Address for reprints: Pim J. de Feyter, MD, Catheterization Laboratory, Thoraxcenter, Bd 414, P.O. Box 1738, 3000 DR Rotterdam, The Netherlands.

\section{Methods}

Between February 1983 and June 1985, 150 patients with unstable angina pectoris underwent PTCA. Unstable angina pectoris was defined as chest pain at rest lasting for at least 15 minules, accompanied by electrocardiographic ST-T changes and no subsequent signs of myocardial necrosis. Sixty-eight patients (58 men, 10 women, mean age 56.3 years, range 31 to 72 ) who fulfilled the following criteria were selected for this study: successful single artery dilatation in patients with unstable angina pectoris; no angiographic restenosis, reocclusion or late reinfarction during follow-up; and serial left ventriculograms of sufficient quality to allow automated contour analysis before PTCA and at follow-up catheterization.

Thirty-two percent of patients had had a myocardial infarction; $19 \%$ had collaterals to the infarct-related vessel. The mean number of documented attacks of pain was $2.8 \pm 2$ and the mean time between the last attack of pain and the left ventriculogram before PTCA was $43 \pm 48$ hours. Treatment consisted of a combination of intravenous nitroglycerin, $\beta$-adrenergic receptor antagonists and calcium antagonists. Forty-four patients $(65 \%)$ who underwent emergency 
PTCA were refractory to treatment. Initial stabilization was achieved in 24 patients (35\%), but they remained symptomatic on slight exertion. These patients underwent elective PTCA.

PTCA was performed with a steerable balloon catheter system. In patients with multivessel disease only the ischemia-related vessel was dilated. ${ }^{14}$ PTCA was considered successful if the severity of obstruction was reduced to less than $50 \%$ of the luminal diameter, with abolition of acute ischemic symptoms and no progression to myocardial infarction or death.

After discharge, treatment with nifedipine, 40 to 60 $\mathrm{mg} /$ day and acetylsalicilic acid, $500 \mathrm{mg} /$ day, was continued for a period of 6 months. Sixty-three of the 68 patients underwent exercise thallium-201 scintigraphy at a mean of 2.8 months (range 1 to 4) after PTCA. Patients performed symptom-limited exercise on the bicycle ergometer with stepwise increments of $20 \mathrm{~W}$ every minute. The 3 orthogonal leads XYZ of the Frank lead system were recorded. An ischemic response was defined as at least $0.1 \mathrm{mV}$ of ST-segment depression of
0.08 second after the J point. The maximal workload achieved was expressed as a percentage of the normal workload predicted for age, sex and body length. Thallium exertional scintigraphic imaging was performed in the anterior, left anterior oblique $45^{\circ}$ and $65^{\circ}$ views, immediately after injection of $1.5 \mathrm{mCi}$ of thallium-201 at peak stress. Postexercise images were recorded 4 hours later. Images were obtained using a Searle Phogamma V camera. Defects with redistribution were considered to represent reversible ischemia.

All patients underwent follow-up catheterization a mean of $3.1 \pm 2$ months after PTCA. A restenosis was defined as an increase of the luminal diameter stenosis of the dilated lesion of more than $50 \%$.

Analysis of global and regional left ventricular function: The coronary angiograms were recorded before left ventricular (LV) angiograms. Global and regional LV function were studied from the $30^{\circ}$ right anterior oblique LV cineangiogram using an automated hard-wired endocardial contour detector linked to a minicomputer. This method of analysis has been
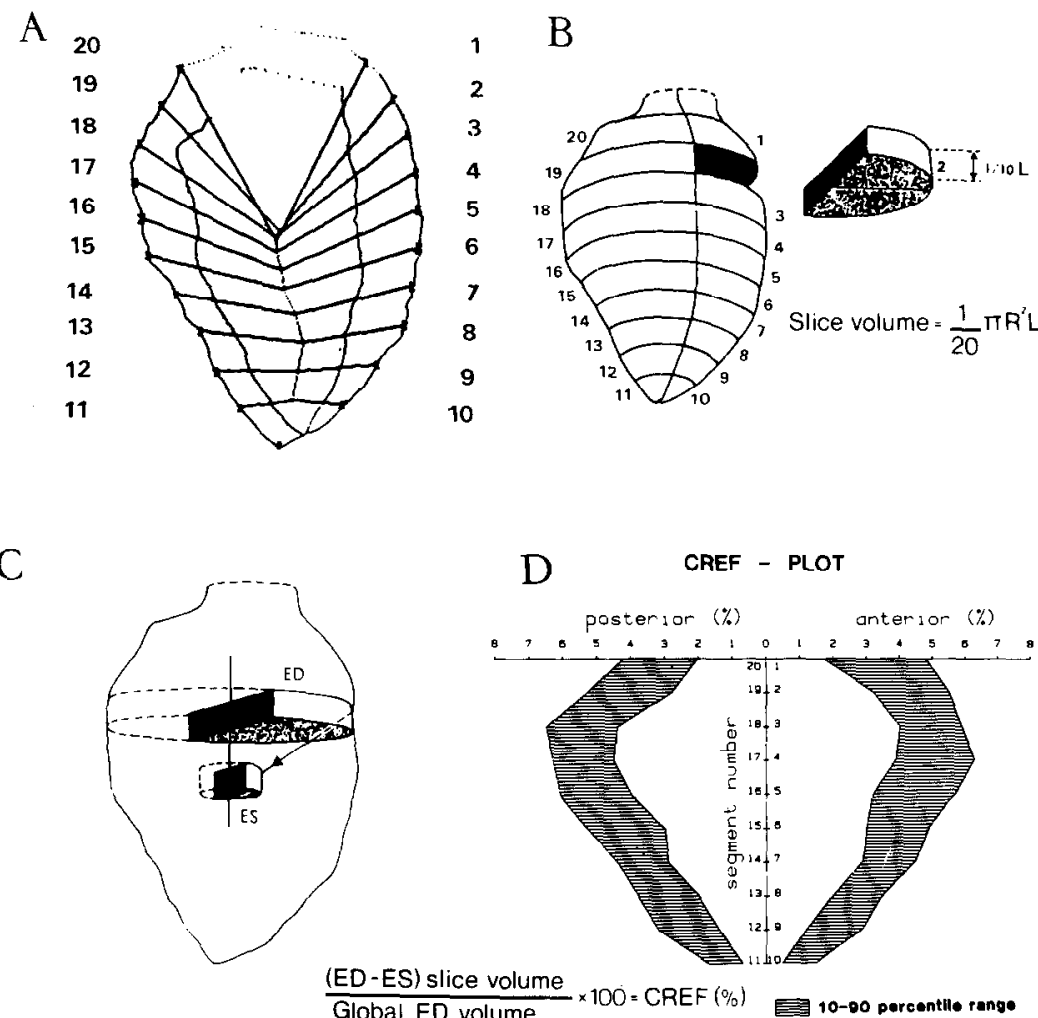

B

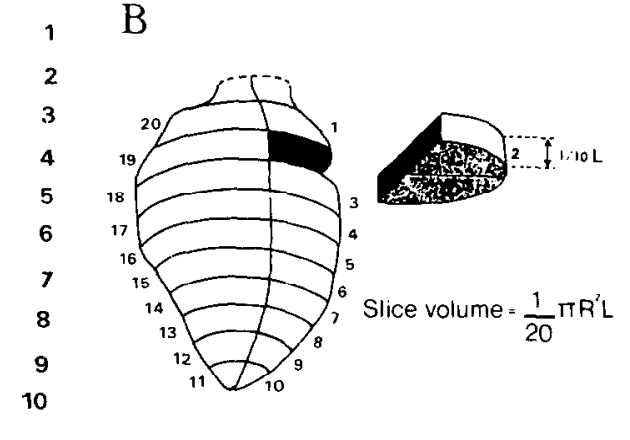

10

.
C

Global ED volume

FIGURE 1. A, example of the computer output showing the end-diastolic (ED) and end-systolic (ES) contours of the $30^{\circ}$ right anterior oblique left ventriculogram. Systolic regional wall displacement was determined along a system of 20 coordinates on the pattern of actual endocardial wall motion in normal persons and generalized as a mathematic expression amenable to automatic data processing. ${ }^{15-18} \mathrm{~B}$, the left ventricular end-diastolic cavity is separated into $\mathbf{2 0}$ half-slices. The volume of each half slice is computed according to the given formula, where $R=$ radius and $L=$ left ventricular long-axis length. $C$, the reglonal contrlbution to global ejectlon fractlon (CREF) Is determined from the systolic decrease of volume of the half slice that corresponds to a particular wall segment. The systolic volume change is mainly a consequence of the decrease of radius $(R)$ of the half slice. When normalized for end-diastolic volume, the systolic segmental volume change was considered as a parameter of regional pump function. During systole this parameter expresses quantitatively the contribution of a particular segment to global ejection fraction. The sum of the values for all 20 segments equals the global ejection fraction. $D$, shaded zones represent the 10th to the 90th percentile area of CREF values in normal persons. On the $x$ axis, the CREF values of the anterior and inferoposterior wall areas are displayed $(\%)$, while on the $y$ axis the segment numbers of the anterior wall (1-10) and of the inferoposterior wall (11-20) are depicted. The segmental CREF values in the anterobasal (segments 1 to 5 ), anterolateral (segments 5 to 9 ), apex (segments 9 to 12), inferoapical (segments 12 to 16) and posterobasal (segments 16 to 20 ) wall regions were analyzed. 
TABLE I Global Left Ventricular Hemodynamics Before (B) and After (A) Successful Percutaneous Transluminal Coronary Angioplasty

\begin{tabular}{|c|c|c|c|c|c|c|c|c|}
\hline \multirow[b]{2}{*}{ Variables } & \multicolumn{2}{|c|}{$\begin{array}{l}\text { All Patients } \\
(n=68)\end{array}$} & \multicolumn{2}{|c|}{$\begin{array}{l}\text { Left Anterior Descending } \\
\text { Coronary Artery } \\
(n=38)\end{array}$} & \multicolumn{2}{|c|}{$\begin{array}{l}\text { Right Coronary Artery } \\
\qquad(n=16)\end{array}$} & \multicolumn{2}{|c|}{$\begin{array}{l}\text { Left Circumflex } \\
\text { Coronary Artery } \\
\qquad(n=14)\end{array}$} \\
\hline & $\mathrm{B}$ & $A$ & B & A & $\mathrm{B}$ & A & B & $A$ \\
\hline HR (bpm) & $72 \pm 12$ & $71 \pm 12$ & $74 \pm 12$ & $70 \pm 10$ & $73 \pm 13$ & $73 \pm 18$ & $68 \pm 13$ & $70 \pm 10$ \\
\hline MAP (mm Hg) & $98 \pm 17$ & $108 \pm 16 \dagger$ & $99 \pm 18$ & $109 \pm 19 \dagger$ & $89 \pm 10$ & $103 \pm 11 \dagger$ & $106 \pm 16$ & $110 \pm 13$ \\
\hline $\operatorname{EDV}\left(\mathrm{ml} / \mathrm{m}^{2}\right)$ & $75 \pm 16$ & $77 \pm 18$ & $74 \pm 15$ & $74 \pm 18$ & $74 \pm 18$ & $79 \pm 22$ & $77 \pm 18$ & $79+14$ \\
\hline $\operatorname{ESV}\left(\mathrm{ml} / \mathrm{m}^{2}\right)$ & $32 \pm 14$ & $30 \pm 15$ & $32 \pm 13$ & $28 \pm 12^{*}$ & $32 \pm 16$ & $35 \pm 21$ & $29 \pm 12$ & $31 \pm 12$ \\
\hline$S V\left(\mathrm{ml} / \mathrm{m}^{2}\right)$ & $43 \pm 10$ & $46 \pm 11$ & $42 \pm 11$ & $46 \pm 11^{*}$ & $43 \pm 8$ & $44 \pm 12$ & $47 \pm 12$ & $48 \pm 9$ \\
\hline$E F(\%)$ & $57 \pm 12$ & $59 \perp 11^{*}$ & $56 \perp 12$ & $60 \pm 10 \dagger$ & $56 \pm 13$ & $54 \pm 14$ & $59 \pm 11$ & $60 \pm 11$ \\
\hline
\end{tabular}

${ }^{*} p<0.05 ; \uparrow p<0.005$.

$\mathrm{EDP}=$ end-diastolic pressure; $\mathrm{EDV}=$ end-diastolic volume; $\mathrm{EF}=$ ejection fraction; $\mathrm{ESV}=$ end-systollc volume; $\mathrm{HR}=$ heart rate; $\mathrm{MAP}=$ mean arterial pressure; $\mathrm{SV}=$ stroke volume.

TABLE II Analysis of the Regional Wall Motion Before (B) and After (A) Successful Percutaneous Transluminal Coronary Angioplasty

\begin{tabular}{|c|c|c|c|c|c|c|}
\hline & \multicolumn{2}{|c|}{$\begin{array}{l}\text { Left Anterior Descending } \\
\text { Coronary Artery } \\
\qquad(n=38)\end{array}$} & \multicolumn{2}{|c|}{$\begin{array}{l}\text { Right Coronary } \\
\text { Artery } \\
(n=16)\end{array}$} & \multicolumn{2}{|c|}{$\begin{array}{l}\text { Left Circumflex } \\
\text { Coronary Artery } \\
\qquad(n=14)\end{array}$} \\
\hline & B & $A$ & B & A & B & A \\
\hline Total analyzed segments & 760 & 760 & 320 & 320 & 280 & 280 \\
\hline Total number of abnormal segments & 322 & 137 & 116 & 75 & 104 & 48 \\
\hline Sum of abnormal CREF value (\%) & $17 \pm 8$ & $23 \pm 10 \dagger$ & $10 \pm 6$ & $13 \pm 7^{*}$ & $16 \pm 8$ & $20 \pm 11^{*}$ \\
\hline Sum of normal CREF value (\%) & $41 \pm 18$ & $40 \pm 18^{*}$ & $46 \pm 18$ & $41 \pm 17^{*}$ & $43 \pm 18$ & $40 \pm 18$ \\
\hline
\end{tabular}

${ }^{*} \mathrm{p}<0.05 ;+\mathrm{p}<0.001$.

$\mathrm{CREF}=$ contribution to regional ejection fraction (see Figure 1).

described in detail.15-18 Figure 1 shows an example of computer output showing the end-diastolic and endsystolic contours of the left ventriculogram and system of coordinates along which segmental wall displacement is determined. The inter- and intraobserver variability of automated assessment of global and regional LV performance ranged between 1.6 and $2.3 \%$ standard error of the cstimate for global cjection fraction; and for summed regional contribution to ejection fraction anterobasal, anterolateral, apex, inferoapical and posterobasal segments, respectively, between 0.4 and $2.3 \%$ standard error of the estimate.

Statistics: Results are expressed as mean \pm standard deviation. Statistics were determined with 2tailed Student $t$ test. A p value $<0.05$ was considered statistically significant.

\section{Results}

Global and regional LV function before and after PTCA were analyzed for all patients and grouped according to the dilated vessel (Tables I and II, Figure 2). Global ejection fraction was significantly improved in patients who had lesions in the left anterior descending artery, which was dilated because of a decrease in end-systolic volume, whereas no significant change in serial global LV function was observed in patients with PTCA of the right or left circumflex coronary artery (Table I). Computer-assisted regional wall mo- tion analysis showed improvement in motion of the initially abnormal segment in all 3 subsets of patients, whereas the regional wall motion decreased to a small extent in initially normal segments (Figure 2, Table II).

The results of thallium-201 scintigraphy are shown in Figure 3. Most of the patients had no signs of myocardial ischemia with a normal exercise tolerance.

\section{Discussion}

In patients undergoing successful PTCA, anatomic improvement correlates well with elimination of angi$\mathrm{na},{ }^{19}$ improved function on atrial pacing ${ }^{20}$ and conventional exercise testing, ${ }^{21-23}$ improved perfusion with myocardial scintigraphy ${ }^{21,22}$ and radionuclide ventriculography, ${ }^{24}$ and restoration to a nearly normal coronary flow reserve. ${ }^{25}$

The myocardium is capable of recovering function lost as a result of ischemia after adequate reperfusion. Whole or partial recovery may occur after successful coronary artery bypass surgery. 9,10,26-28

In this study, we demonstrated that successful PTCA was accompanied by improvement in global LV function in patients with dilatation of a lesion of the left anterior descending coronary artery and by significant improvement of $\mathrm{LV}$ regional wall motion in the initially impaired regional segments of the areas perfused by the left anterior descending, circumflex and 


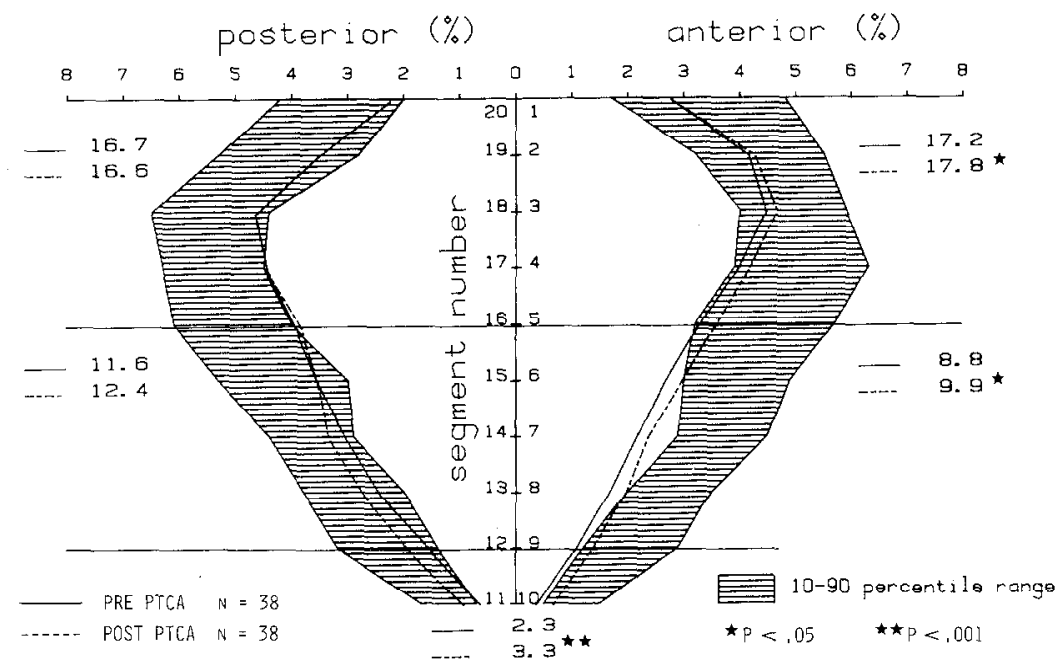

RCA GROUP

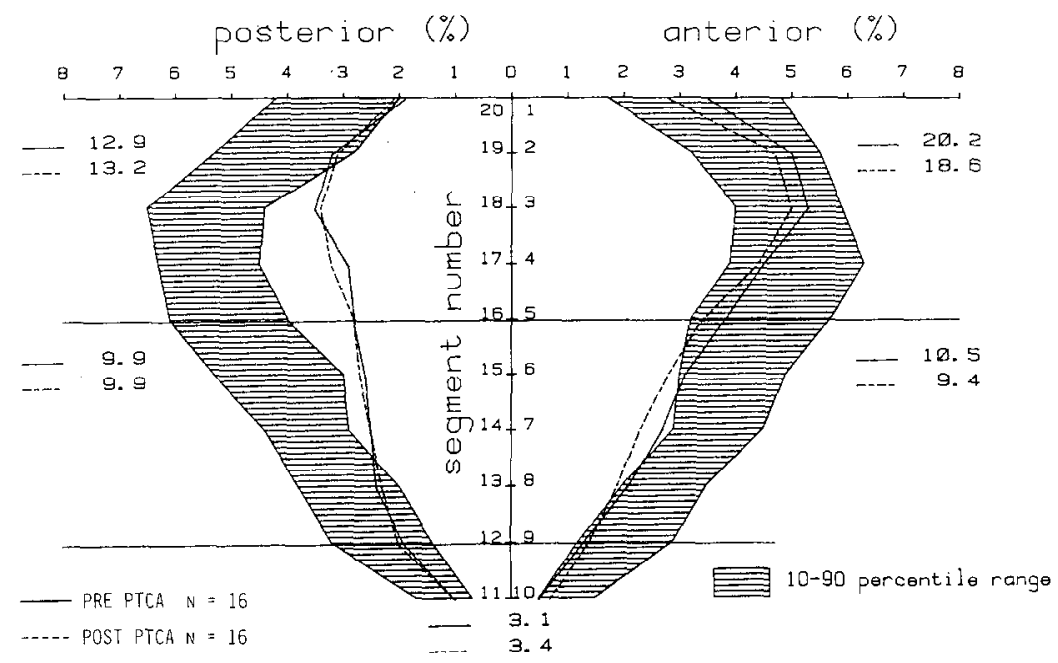

FIGURE 2. Left ventricular regional wall motion in 38 patients with a stenosis of the proximal left anterior descending (LAD) coronary artery $(A)$, in 16 patients with a stenosis of the right coronary artery (RCA) (B), and in 14 patients with a stenosis in the left circumflex coronary artery (LCX) (C) before and after percutaneous transluminal coronary angioplasty (PTCA).

LCX GROUP

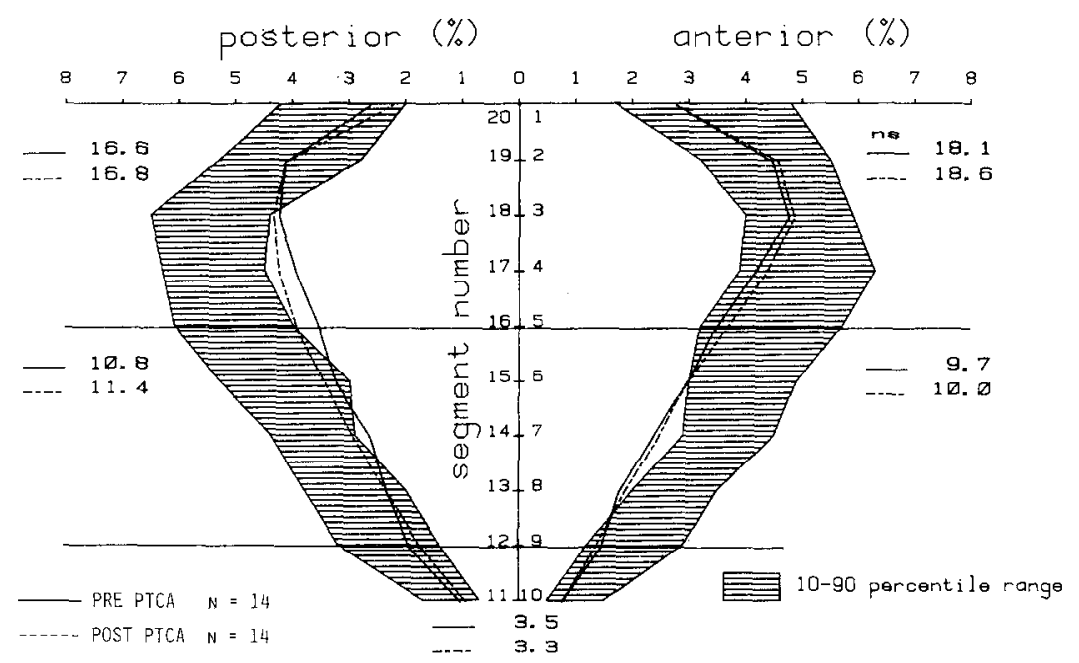




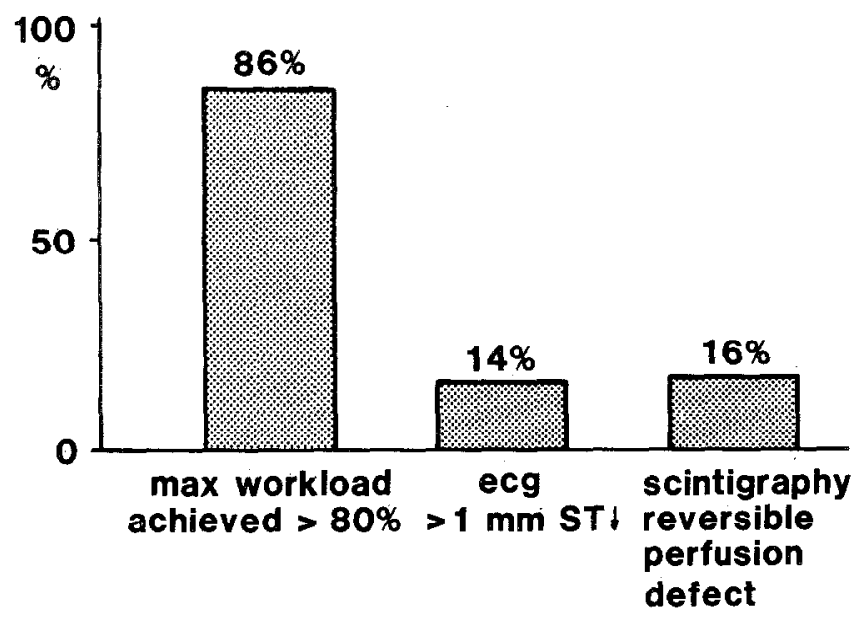

FIGURE 3. Results of exercise thallium-201 scintigraphy in 63 patients after successful percutaneous transluminal coronary angioplasty. ecg = electrocardiogram.

right coronary arteries. The improvement (left anterior descending group) or maintenance (right coronary artery and left circumflex groups) of LV global ejection fraction was primarily due to improvement of the initially abnormal regional wall motion, even after the disappearance of the compensatory actions of the initially enhanced function of the nonischemic segments.

Limitations: Myocardial dysfunction as a result of prolonged ischemia may improve spontaneously when the ischemic attacks resolve spontaneously either as part of a natural healing process or as a result of pharmacologic therapy. ${ }^{29}$ Ideally, the effects of PTCA on $\mathrm{LV}$ function should be determined in a randomized, controlled study, but it is difficult to justify this type of study in our group of patients due to severity of the disease. We believe that the normalization of anterograde flow after PTCA, as evidenced by repeat angiography and no signs of ischemia in most of the patients who underwent exercise thallium-201 scintigraphy, is the main reason for the observed recovery of myocardial function.

Differences in pharmacologic treatment before and after PTCA, in particular the use of $\beta$-adrenergic blockade before PTCA, may also play a role in the observed difference of $\mathrm{LV}$ function. However, we have shown that regional wall motion improved selectively in the areas that received better blood supply after PTCA rather than in the ventricle as a whole.

Acknowledgment: We thank Gusta Koster and Anja van Huuksloot for preparing the manuscript.

\section{References}

1. Heyndrickx GR, Baig H, Nellens D, Leusen MC, Fishbein MC, Vatner SF Depression of regional blood flow and wall thickening after brief coronary occlusion. Am J Physiol 1978;234:H653-659.

2. Vafner SF. Correlation between acute reductions in myocardial blood flow and function in conscious dogs. Circ Res 1980;47:201-207.

3. Braunwald E, Kloner RA. The stunned myocardium: prolonged, postischemic ventricular dysfunction. Circulation 1982;66:1146-1149.

4. Constantini C, Corday E, Lang T, Meerbaum S, Brasch J, Kaplan L, Rubins $\mathrm{S}$, Gold $\mathrm{H}$, Osher J. Revascularization after three hours of coronary arterial occlusion: effects on regional cardiac metabolic function and infarct size. Am f Cardiol 1975;36:368-384.

5. Theroux P, Ross I, Franklin D, Kemper SW, Sasayama S. Coronary arterial reperfusion. Early and late effects on regional myocardial function and dimensions in conscious dogs. Am J Cardiol 1976;38:599-606.

6. Matsuzaki M, Gallagher KP, Kemper WS, White F, Ross J. Sustained re gional dysfunction produced by prolonged coronary stenosis: gradual recovery after reperfusion. Circulation 1983;68:170-182.

7. Rees G, Bristow JD, Kremkau EL, Green GS, Herr RH; Griswold HE, Starr A. Influence of aorta coronary bypass surgery on left ventricular performance. $N$ Engl I Med 1971;284:1116-1120.

8. Bourassa MG, Lespérance I, Campeau L, Saltiel ]. Fate of left ventricular contraction following aortocoronary venous grafts. Circulation 1972;46:724730 .

9. Chatterjee K, Swan HJC, Parmley WW, Sustaita II, Marcus IIS, Matloff J. Influence of direct myocardial revascularization on left ventricular asynergy and function in patients with coronary heart disease. Circulation 1973;47:276286 .

10. Brundage BH, Massie BM, Botvinick EH. Improved regional ventricular function after successful surgical revascularization. JACC 1984;3:902-908. 11. Anderson JL, Marshall HW, Askins JC, Yanowitz FG, Lutz JR, Sorensen SG, Menlove RL, Hagan AD. A randomized trial of intravenous and intracoronary streptokinase in patients with acute myocardial infarction. Circulation 1984;70:606-618.

12. Serruys PW, Simoons ML, Suryapranata $H$, Vermeer F, Wijns $W$, van den Brand M, Bär F, Zwaan C, Krauss H, Remme W], Res J, Verheugt FWA, van Domburg R, Lubsen J, Hugenholtz PG. Preservation of global and regional left ventricular function after early thrombolysis in acute myocardial infarction. IACG 1986;7:729-742.

13. Erbel R, Pop T, Henrichs K, Olshausen K, Schuster CJ, Rupprecht H, Steuernagel C, Meyer J. Percutaneous transluminal coronary angioplasty af ter thrombolytic therapy: a prospective controlled randomized trial. IACC $1986 ; 8: 485-495$

14. de Feyter PJ, Serruys PW, Arnold A, Simoons ML, Wijns W, Geuskens R, Soward A, van den Brand $M$, Hugen holtz PG. Coronary angioplasty of the unstable angina related vessel in patients with multivessel disease. Eur Heart I $1986 ; 7: 460 \sim 467$

15. Slager GJ, Reiber IHC, Schiurbiers ICH, Meester GT Contouromat: a hardwired left ventricular angio processing system. Design and application. Comput Biomed Res 1978;11:491-502.

16. Slager CJ, Hooghoudt TEH, Serruys PW, Schuurbiers JCH, Reiber JHC, Meester GT, Verdouw PD, Hugenholtz PG. Quantitative assessment of regional left ventricular motion using endocardial landmarks. I ACC 1986,7:317326.

17. Serruys PW, Wijns W, van den Brand M. Left ventricular performance, regional blood flow, wall motion and lactate metabolism during transluminal angioplosty. Circulation 1984;70:25-36.

18. Serruys PW, Suryapranata $H$, Planellas J, Wijns W, Vanhaleweyck GLJ, Soward A, Jaski BE, Hugenholtz PG. Acute effects of intravenous nisoldipine on left ventricular function and coronary hemodynamics. Am I Cardiol 1985;56:140-146.

19. Gruentzig AR, Sennig A, Siegenthaler WE. Non-operative dilatation of coronary artery stenoses: percutaneous transhuminal coronary angioplasty. $N$ Engl I Med 1979;301:61-68.

20. Williams DO, Riley RS, Singh AK, Most AS. Restoration of normal coronary hemodynamics and myocardial metabolism after percutaneous transluminal coronary angioplasty. Circulation 1980:62:653-656.

21. Hirzel HO, Neusch K, Gruentzig AR, Luetolf UM. Short- and long-term changes in myocardial perfusion after percutaneous transluminal coronary angioplasty assessed by thallium-201 scintigraphy. Circulation 1981;63:10011007.

22. Scholl J, Chaitman BR, David PR, Dupras G, Brevers G, Val PG, Crépeau ], Lesperance J, Bourassa MG. Exercise electrocardiography and myocardial scintigraphy in the serial evaluation of the results of percutaneous transh minal coronary angioplasty. Circulation 1982;66:380-389.

23. Meier B, Gruentzig AR, Siegenthaler WE, Schlumpf M. Long-term exer cise performance after percutaneous transluminal coronary angioplasty and coronary artery bypass grafting. Circulation 1983;68:796-802.

24. Kent KM Bonow RO, Rosing DR, Ewels GI, Lipson LC, McIntosh CL, Bacharach S, Green M, Epstein SE. Improved myocardial function during exercise after successful percutaneous transluminal coronary angioplasty. $N$ Engl J Med 1982;306:441-446.

25. O'Neill WW, Walton JA, Bates ER, Bourdillon PD, Kryski T', Pitt B. Criterid for successful coronary angioplasty as assessed by alterations in coronary vasodilatory reserve. JACC 1984;3:382-390.

26. Berger BC, Watson DD, Burwell LR, Crosby IK, Wellons HA, Teates CD Beller GA. Redistribution of thallium at rest in patients with stable and unstable angina and the effect of coronary artery bypass surgery. Circulation 1979;60:1114-1125.

27. Kolibash AJ, Goodenow JS, Bush CA, Tetalman MR, Lewis RP. Improvement of myocardial perfusion and left ventricular function after coronary artery bypass grafting in patients with unstable angina. Circulation 1979 $59: 66-74$.

28. Tillisch J, Brunken R, Marshall R, Schwaiger M, Mandelkorn M, Phelps $\mathrm{M}$, Schelbert $\mathrm{H}$. Reversibility of cardiac wall motion abnormalities predicted by positron tomography. $N$ Engl / Med 1986;314:884-888.

29. Nixon JV, Brown CN, Smitherman TC. Identification of transient and persistent segmental wall motion abnormalities in patients with unstable angina by two-dimensional echocardiography. Circulation 1982;65:1497. 